\title{
Assessment of the combined usefulness in thyroid function testing of the triiodothyronine resin-sponge and 24-hour iodine uptakes
}

\author{
R. A. CARTER \\ From the Department of Pathology, East Birmingham General Hospital
}

SYNOPSIS Iodine and resin sponge uptake tests have been performed upon 124 consecutive patients referred for thyroid studies. Neither test alone could correctly identify all cases of thyrotoxicosis or myxoedema, but when considered in combination diagnostic efficiency was much improved. The combination of tests is shown to be especially useful in the investigation of patients with changes body iodine pools or thyroxine-binding globulin levels.

Reasons are given for regarding this pair of tests as being more generally useful than any of the other possible combinations at present available. The resin sponge test kit was found to be satisfacto $\frac{\overline{\underline{Y}}}{3}$ both technically and in respect of cost.

In 1957 Hamolsky, Stein, and Freedberg described a test based upon the partition of radioactively labelled triiodothyronine (T3) between plasmabinding sites and erythrocytes. This test has now been widely used and evaluated (Hamolsky, Golodetz, and Freedberg, 1959; Ureless and Murray, 1959; Robbins, 1959; Friis, 1960; Young, Nicholas, MacGregor, and Rusted, 1960; Wagner, Nelp, and Watts, 1961; Walfish, Britton, Volpe, and Ezrin, 1961). However, its usefulness as an addition to commonly performed tests of thyroid function has been somewhat limited by the ease with which labelled $\mathrm{T} 3$ is eluted from the red cells during washing (Tauxe and Yamaguchi, 1961), by the need for a rather lengthy and scrupulously standardized technique, and by difficulties with the supply of a satisfactory preparation of ${ }^{131} \mathrm{I}-\mathrm{T} 3$ (Osorio, personal communication). In an attempt to overcome the first two difficulties a test was devised in which the labelled T3 was partitioned between serumbinding sites and Amberlite I R A 400 enmeshed in a polyurethane-foam sponge (Mitchell, Harden, and O'Rourke, 1960). The use of a sponge was claimed to yield more consistent results than were found using resin in granular form, although other workers have found the latter satisfactory (Sterling and Tabachnick, 1961; Nava and De Groot, 1962; Quimby and Hiza, 1964). The need for a centrifuge was also dispensed with.

The theoretical basis of the test is that the greater

Received for publication 15 December 1965. the output of thyroxine from the thyroid the moge fully will the binding sites on the thyroxine-binding globulin be occupied. As a consequence more of added sample of $\mathrm{T} 3$ will pass to other binding sits in a test mixture, e.g., red cells or resin. T3 is prgferred to thyroxine as test substance because its weaker binding by thyroxine-binding globulin givess a more nearly equal partition in practice. The principal disadvantage of the test is that factoons raising or lowering the amount of thyroxine-binding globulin will also influence the outcome. These factors operate in many conditions, e.g., pregnanct, renal disease, anticoagulant and anticonvulsaunt therapy, but fortunately do not operate often in uRcomplicated thyrotoxicosis or myxoedema. The thre⿸\zh14 great advantages of the test are that the patient does not have to be present, no radioactive substance administered to the patient, and the results are not influenced by the presence of iodine-containing substances in the body or by changes in body poofs of inorganic iodide.

Since the factors which may invalidate this test, by leading to changes in the thyroxine-binding globulie, are quite independent of the factors which may dio tort the iodine uptake (chiefly changes in the size of the body iodide pool), it should be possible to obtam superior results in assessment of thyroid function bP considering both tests together.

MATERIALS AND METHODS

Blood was taken from all patients referred for iodike 128 
uptake measurements, and after separation (within one to two hours) the serum was stored at $-20^{\circ} \mathrm{C}$. The test kits (Triosorb, Abbott Laboratories) were imported by air from the U.S.A. once a month and were distributed by post from London. On receipt two to four days later they were refrigerated at $+4^{\circ} \mathrm{C}$. till used. As soon as convenient all sera accumulated were tested according to the instructions provided with the kit. Briefly these are that $1 \mathrm{ml}$. of serum is pipetted into the disposable tube provided. This is followed by the contents of a syringe consisting of ${ }^{131}$ I-labelled T3 in a suitable buffer, and the resin sponge is added at once. The air is expressed from the meshes of the sponge by a plastic rod provided in the kit. Incubation is now carried out for exactly one hour at a known temperature (preferably $25^{\circ} \mathrm{C}$.) and during this time the sample is counted in a well-type $\mathrm{Na}$ I crystal scintillation counter. After one hour the serum is withdrawn, using a plastic compressor-aspirator attached to a reservoir for radioactive waste and operated by a filter pump. Three washes of distilled water follow, using the compressor-aspirator, and the dry sponge is counted again. The result is calculated thus:-

$\frac{\text { Second count }- \text { background }}{\text { First count }- \text { background }} \times 100=\%$ sponge uptake

Normal values at $25^{\circ} \mathrm{C}$. are $25-35 \%$ and temperature correction data are provided.

Twenty-four-hour iodine uptakes were performed initially using $15 \mu \mathrm{C}$ of ${ }^{131} \mathrm{I}$ orally, and were read with a ring of $4 \mathrm{G} 10 \mathrm{~Pb}$ geiger tubes. During the course of this study this was changed to a $10 \mu \mathrm{C}$ dose of ${ }^{125} \mathrm{I}$, read with a special thin $\mathrm{Na} I$ crystal scintillation counter and a conical 6 in. collimator. Normal values were $27-50 \%$ uptake with both techniques, and values between 50 and $60 \%$ were regarded as equivocal. Readings of effective half-life were taken in many patients and have been taken into account in determining the final diagnosis in some doubtful cases. Further uptake tests were performed after giving thyroid-stimulating hormone or $\mathrm{T} 3$ in a number of instances. Determinations of the protein-bound iodine were made at Staffordshire General Infirmary (Pick, Sanderson, Ward, and Waterhouse, 1965) in about half the cases studied.

\section{RESULTS}

One hundred and twenty-four consecutive patients were studied by iodine and Triosorb sponge uptake. At the end of the study period they were reviewed and placed into various diagnostic categories on the basis of the clinical findirgs, the response to treatment, and a consideration of all the available laboratory test results.

THYROTOXICOSIS GROUP Twenty-seven patients were judged on the above criteria to fall into this category, and their test results are shown in Figure 1. It is evident that the majority were easily identified by either test, but in three instances iodides or iodinecontaining contrast media had been given, unknown

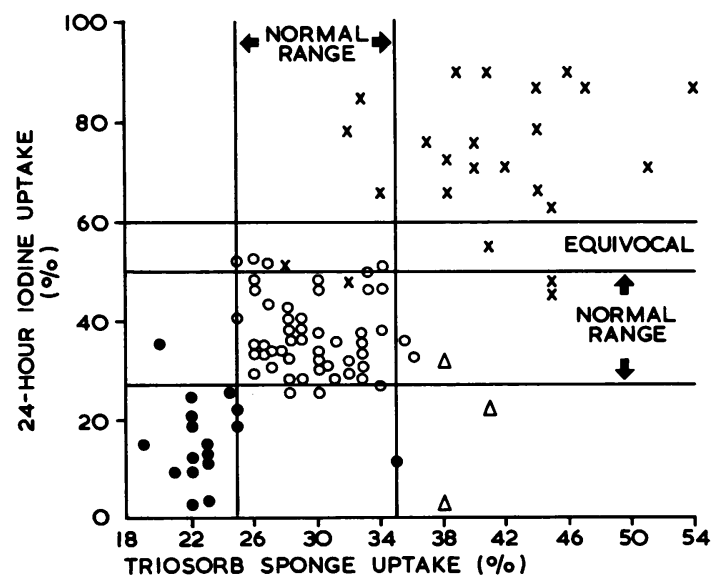

FIG. 1. Twenty-four-hour iodine uptakes and Triosorb sponge uptakes of patients in groups 1-3. $\times$ Thyrotoxic (group 1). Hypothyroid (group 2). $\bigcirc$ Judged euthyroid (group 3). $\triangle$ Thyrotoxic patients with recent iodine dosage (group 1).

to the person requesting an uptake. In these the iodine uptake was low, but the sponge result remained unequivocally high. Three other patients had 24-hour uptakes within the normal or equivocal range, but with shortened effective half lives. In these the sponge uptake and protein-bound iodine levels were both elevated. These six cases thus represent successes for the sponge uptake and failures for the 24-hour iodine uptake. By contrast three patients with normal sponge uptakes had unequivocally raised 24-hour uptakes. In two of these the protein-bound iodine was determined and was abnormally high, whilst all three were clinically hyperthyroid. A further two cases had 24-hour uptakes near the upper limit of normal and normal sponge uptakes. Both showed shortened effective half lives, in one the protein-bound iodine was estimated and was high, whilst the other showed no suppression of uptake by T3 dosage. Thus these two cases were double failures for both techniques, although when the investigations were further supplemented by estimating the protein-bound iodine, the effective thyroidal half life of ${ }^{131} \mathrm{I}$, and B.M.R. the clinical diagnosis of thyrotoxicosis was confirmed.

HYPOTHYROIDISM Seventeen patients fell into this category, and their results are also shown in Figure 1. Only one yielded a sponge uptake which was frankly normal, whilst two others were on the borderline. These three patients all had low 24-hour iodine uptakes and showed no response to stimulation by thyroid-stimulating hormone. One other patient with clinical myxoedema, high serum cholesterol level, 
and a low sponge uptake showed a normal 24-hour uptake.

JUDGED EUTHYROID This was a much harder group to define; it comprised 51 patients who appeared normal by at least two tests of thyroid function and who had been referred more to exclude any possibility of thyroid disorder than because this was clinically considered to be present. It is remarkable how many such patients are seen by those who undertake thyroid diagnostic work. They include many subjects with single symptoms which might be due to latent thyroid dysfunction, such as, weight loss, diarrhoea, palpitations, intolerance of cold, and loss of hair. Reference to Fig. 1 shows that of this group only two patients fell just above the upper limit of normal for the sponge uptake test and none below. The scatter for iodine uptake was greater, three just below and four just above the usually quoted limits.

SMALL IODINE POOL This group comprised 14 patients with iodine uptakes in the equivocal or elevated ranges, but exhibiting a prolonged effective half life. Most had obvious goitres, usually present for many years, but clinically their thyroid status was uncertain. The results of the tests are shown in Figure 2. Only two had sponge uptakes outside the normal range (one just above and one some way below the normal). The majority of these patients had protein-bound iodine determined, and all were normal, and many had T3 suppression tests which uniformly showed a normal response. This group causes much diagnostic difficulty, and it is clear that the sponge uptake is most useful in investigating such patients.

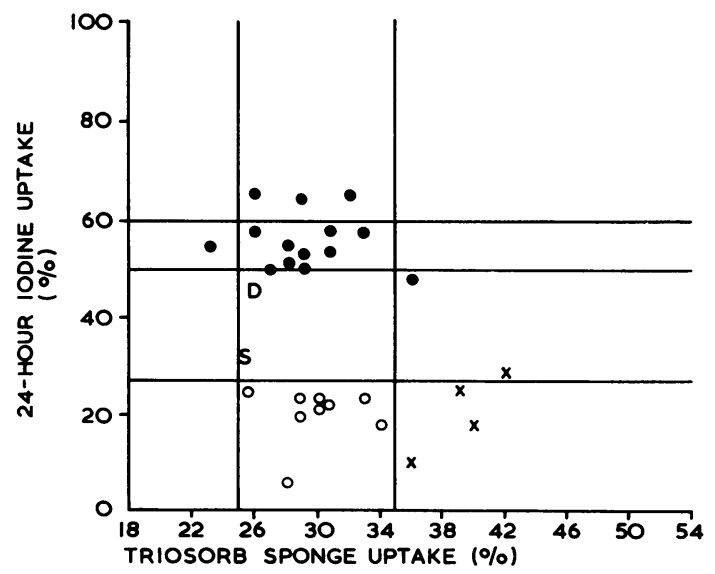

FIG. 2. Twenty-four-hour iodine uptakes and Triosorb sponge uptakes of patients in groups 4-6. Small iodine pool (group 4). $\bigcirc$ Large iodine pool (group 5). $\times$ 'Very ill', S Simmond's disease, D dyshormonogenesis (group 6).
ENLARGED IODINE POOL These nine patients were judged euthyroid by clinical findings and by estimat: ing the basal metabolic rate. The protein-boun iodine was also normal but the iodine uptake was low, and, as will be seen in Fig. 2, the sponge uptak was normal in all cases. Several gave a history of ingestion of substances likely to raise the iodine poब or of the use of $x$-ray contrast media, often many months before investigation in this study. The normal values found for protein-bound iodine migl indicate that the blood iodide level was not gross raised or it might be due to inorganic iodine cors tamination of a sample in which the true value fợ protein-bound iodine was subnormal. Again the sponge uptake emerges as a most useful aid to investigation.

ANOMALIES AND RARITIES Four patients who were very ill and appeared clinically somewhat hypermetabolic showed low iodine uptakes and higt sponge uptakes. These patients, one of whom hat nephrosis and another advanced carcinomatosiş, presumably had a reduced thyroxine-binding globuli $\vec{b}$ value permitting adequate or excessive unbouns thyroxine to be supplied to the tissues from a smallex than normal thyroid gland activity. Here the sponge test clearly fails to distinguish these patients frorm those with masked thyrotoxic cardiac failure, but the iodine uptake succeeds. The one patient whos protein-bound iodine was determined had a low normal level which is what one would predict i these circumstances.

A patient with dyshormonogenesis showed a low value for protein-bound iodine, a low normal sponge uptake, and a normal 24-hour uptake with a greatly shortened half life. The findings suggested a combination of rapid loss of iodide from the gland wit increased proportion of hormones other thas thyroxine in the output. A patient with classica hypopituitarism showed results just within normad for both sponge and 24-hour uptakes, but increased the latter considerably after thyroid-stimulating hormone.

PREGNANCY No cases were studied, but it may bS inferred from published work (Wayne, Koutras, and Alexander, 1964) that the sponge uptake will be vero low, whilst the iodine uptake will be normal or high so separating this group from all the others above.

CORRELATION BETWEEN PROTEIN-BOUND IODINE ANDD SPONGE UPTAKES Results of both tests were availo able for 48 patients, and these are plotted in Figure $3 \stackrel{\mathbb{Q}}{\Omega}$ If the thyroid-bound globulin remained constant irg amount there should be a close linear correlations between the two. In the figure it can be seen that 


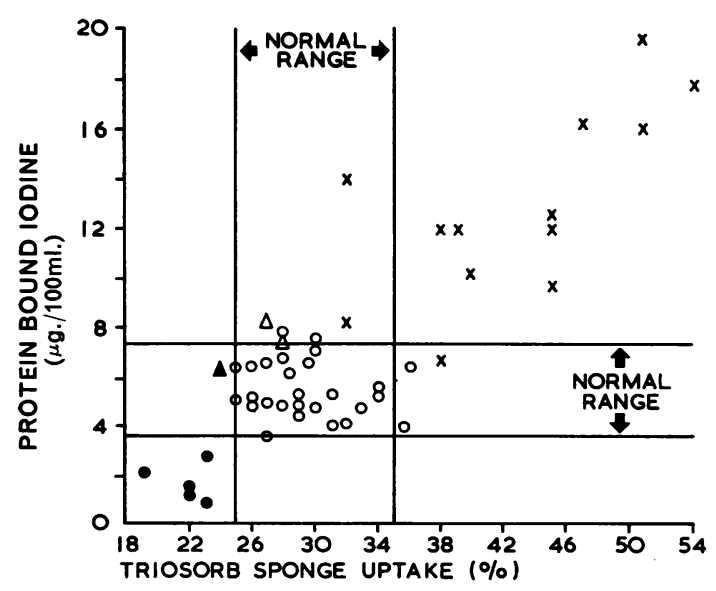

FIG. 3. Protein-bound iodine determinations and Triosorb sponge uptakes. $\times$ Thyrotoxic. Hypothyroid $\bigcirc$ Euthyroid, including some group 4 and 5 patients. $\triangle$ Euthyroid with definite history of iodine ingestion or dosage. A Hypothyroid with similar history.

there is a rough correlation, but the amount of scatter indicates the variability in the size of the pool of thyroxine-binding globulin encountered in clinical practice, or perhaps in its avidity.

\section{DISCUSSION}

It is clear from the foregoing results that the resin sponge uptake test is a useful addition to laboratory procedures for investigating thyroid function, and that the prediction that its value would be enhanced by considering it in conjunction with the 24-hour iodine uptake has also been fulfilled. This test, like all other single tests of thyroid function, fails to identify all cases of hyperthyroidism, presumably because some have a small thyroxine-binding globulin pool and perhaps because others synthesize a larger than normal proportion of the less tightly bound hormone T3 (Wayne et al., 1964). Diagnostic success with myxoedema cases in this series has been superior to that of most workers, who have found appreciable overlap between this group and the euthyroid patients (e.g., Mitchell et al., 1960; Wagner et al., 1961). The reason for this is not clear. The demonstration of a negative finding is always more difficult than making a definite diagnosis, and the sponge test has been very useful in supporting results for iodine uptake in the large group of patients submitted for exclusion of thyroid dysfunction in whom normal figures were found. Its especial usefulness where there has been disturbance in the size of the body iodine pool has already been referred to.

The pattern of results obtained in this study bears a close resemblance to that figured by Gimlette (1965) using a combination of the dialysable thyroxine and the plasma thyroxine. These are both tests in vitro using radioactive thyroxine; the former gives results correlating closely with the red cell T3 uptake (Gimlette, 1964) while the latter should closely follow the protein-bound iodine. For those already equipped with facilities for isotope investigation the two tests proposed by Gimlette have the great advantages that only blood samples are needed in the laboratory and no radioactive substances are given to the patient. Their disadvantages are that they require a great deal more bench time, more equipment, and a more elaborate technique than the pair of tests used in this study. Except in those patients for whom isotope investigation in vivo is contraindicated (the young and the pregnant) preference will depend on local circumstances. Where laboratory facilities are generous and technical staff readily available the two tests in vitro will be favoured, but where time and facilities are limited the iodine and sponge uptakes would seem preferable.

Would any other pair of investigations be as good? The present study does not allow this question to be answered directly, but it is likely that the combination of test for iodine uptake and protein-bound iodine would be nearly as good, except when one is dealing with the 'very ill' group or with patients on drugs which lower the thyroxine binding, e.g., anticoagulants and some anticonvulsants (Walfish et al., 1961; Oppenheimer, Fisher, Nelson, and Jailer, 1961). These are clearly picked out by the tests used in this study and by Gimlette (1965), but would be confused with the hypothyroid group by protein-bound iodine and uptake. Reference to the results obtained in this study suggests that the patients with an enlarged iodine pool (low uptake and high-normal proteinbound iodine) would be more clearly separated from the others, while the small pool cases would show a similar separation to that obtained in this study. The combination of protein-bound iodine and sponge uptake (Fig. 3) gives excellent results for the identification of hypothyroid, euthyroid, and hyperthyroid groups, and is of course very similar to Gimlette's pair of investigations. It has the advantage over them of being simpler to perform, while still needing only blood samples. It will also identify conditions with anomalies of the thyroxine-binding globulin, e.g., pregnancy and severe illness, but will not separate those with alterations of the iodine pool, such as iodine-deficient non-toxic goitres, from the euthyroid patients. In this respect it is inferior to the pair of tests proposed here, but because this last 
objection will not be considered important by some it will probably prove a very attractive combination to many hospitals, especially if their biochemistry laboratories are already providing determinations of protein-bound iodine.

The Triosorb test itself is an improvement on the original red cell $\mathrm{T} 3$ uptake test because it involves considerably less time, needs less equipment, and is highly reproducible so that results can be compared from laboratory to laboratory. The large effect of small differences in technique made this difficult with the original test. It is also reasonably priced by comparison with other isotope tests, protein-bound iodine determinations and enzyme kits, as even after importation from the U.S.A., it costs approximately $£ 1$ per test.

I should like to thank Mr. J. H. Michell for permission to reproduce results for protein-bound iodine supplied by his laboratory, and Drs. R. G. F. Parker and H. G. Sammons for their help in reading the manuscript.

\section{REFERENCES}

Friis, T. (1960). Acta endocr. (Kbh.), 33, 117

Gimlette, T. M. D. (1964). J. clin. Path., 17, 58.

- (1965). Ibid., 18, 293.

Hamolsky, M. W., Stein, M., and Freedberg, A. S. (1957). J. c) Endocr., 17, 33.

_-, Golodetz, A., and Freedberg, A. S. (1959). Ibid., 19, 103. Mitchell, M. L., Harden, A. B., and O'Rourke, M. E. (1960). Ibiळ $20,1474$.

Nava, M., and De Groot, L. J. (1962). New Engl. J. Med., 266, 1309. Oppenheimer, J. H., Fisher, L. V., Nelson, K. M., and Jailer, J. $\mathscr{Q}$ (1961). J. clin. Endocr., 21, 252.

Pick, F. J., Sanderson, C., Ward, S. P., and Waterhouse, J. A. (1965) J. clin. Path., 18, 127.

Quimby, E. H., and Hiza, E. (1964). J. nucl. Med., 5, 489

Robbins, L. R. (1959). J. clin. Endocr., 19, 1292.

Sterling, K., and Tabachnick, M. (1961). Ibid., $21,456$.

Tauxe, W. N., and Yamaguchi, M. Y. (1961). Amer. J. clin. Pa舟. 36, 1 .

Ureless, A. L., and Murray, M. (1959). J. Lab. clin. Med., 54, 178 (0)

Wagner, H. N. Jr., Nelp, W. B., and Watts, J. C. (1961). Bull. Johns Hopk. Hosp., 108, 161

Walfish, P. G., Britton, A., Volpe, R., and Ezrin, C. (1961). Can®ึ? med. Ass. J., 84, 637.

Wayne, E. J., Koutras, D. A., and Alexander, W. D. (1964). Clinical Aspects of Iodine Metabolism. Blackwell, Oxford.

Young, R. W., Nicholas, W. C., MacGregor, P. A., and Rusted, (1960). Canad. med. Ass. J., 83, 1160. 